Cite this: RSC Advances, 2013, 3, 18643

Received 12th April 2013, Accepted 29th July 2013

DOI: $10.1039 / c 3 r a 43842 b$

www.rsc.org/advances

\section{Exploring polymer/nanoparticle hybrid solar cells in tandem architecture $\dagger$}

\author{
Verena Kaltenhauser, ${ }^{\text {ab }}$ Thomas Rath, ${ }^{\text {a }}$ Michael Edler, ${ }^{\text {ab }}$ Angelika Reichmann ${ }^{c}$ \\ and Gregor Trimmel*ab
}

\begin{abstract}
Tandem solar cells offer the possibility to significantly enhance solar cell performance through harvesting a broader part of the solar spectrum by using complementary absorbing materials. We report on tandem solar cells, with at least one polymer/nanoparticle hybrid layer as absorber material, in which the nanoparticles are prepared in situ by thermal decomposition of metal xanthates directly in the polymer matrix. In a first series, we investigated a hybrid-organic tandem solar cell, with a hybrid solar cell consisting of the silafluorene containing low band gap polymer PSiF-DBT and copper indium sulphide (CIS) nanoparticles as the bottom cell, and a low band gap polymer (PTB7)/fullerene derivative (PC 61 BM) organic solar cell as the top cell in order to study different recombination layers. Tandem devices with open circuit voltages nearly reaching the sum of the individual cells have been realised. The short circuit current is equal to the value of the hybrid single cell and a fill factor above $50 \%$ is obtained, leading to power conversion efficiencies of about $4.1 \%$. Furthermore, the first results on hybrid-hybrid tandem solar cells consisting of two PSiF-DBT/CIS solar cells are presented. Although the preparation of these double hybrid devices is challenging because of the necessity of two thermal annealing steps, the resulting multilayer stack reveals smooth and homogeneous layers with sharp interfaces. The first working hybridhybrid tandem solar cells still exhibited $81 \%$ of the sum of the open circuit voltages of the single junction solar cells.
\end{abstract}

\section{Introduction}

In the field of organic photovoltaics the concept of tandem solar cells is extensively researched. ${ }^{1-5}$ Tandem solar cells already exceed the efficiencies of solar cells with one absorbing layer in the case of polymer/fullerene and small molecule solar cells. ${ }^{6-9}$ The reasons for that are that challenges of many organic materials like narrow absorption bands or the limited active layer thickness and thus limited absorption due to low hole mobility can be overcome by a tandem configuration. By stacking solar cells with complementary absorbing materials, the absorption range is extended in the best case from the UV-part up to the IR-region, and, in addition to that, the subcells can have thinner absorber layers compared to a single cell to harvest the same amount of photons or even more, which largely reduces the problems associated with low carrier mobilities.

${ }^{a}$ Institute for Chemistry and Technology of Materials, Graz University of Technology, Stremayrgasse 9, 8010 Graz, Austria.E-mail: thomas.rath@tugraz.at

${ }^{b}$ Christian Doppler Laboratory for Nanocomposite Solar Cells, Graz University of Technology, Austria

${ }^{c}$ Institute for Electron Microscopy and Nanoanalysis, Graz University of Technology \& Graz Centre for Electron Microscopy, Steyrergasse 17, 8010 Graz, Austria

† Electronic supplementary information (ESI) available. See DOI: 10.1039/ c3ra43842b
For hybrid solar cells having absorber layers consisting of conjugated polymers and inorganic semiconducting nanoparticles, ${ }^{10-14}$ the tandem concept is entirely not explored up to now, even though this concept bears the chance to significantly improve the efficiencies of hybrid solar cells. Similar to classical organic solar cells, low charge carrier mobilities are often observed. The absorption range in single junction hybrid solar cells can be already extended by choosing proper inorganic semiconductors, e.g. NIR-absorbing $\mathrm{PbS}$ nanoparticles. ${ }^{15}$ Therefore, the tandem architecture gives the auspicious possibility to tune the absorption properties of the solar cells using four materials with complementary absorption profiles in order to harvest as much sunlight as possible.

Up to now, a large variety of hybrid materials consisting of conjugated polymers and inorganic semiconducting nanoparticles with different absorption properties (e.g. $\mathrm{ZnO},{ }^{16} \mathrm{CdS},{ }^{17,18}$ CdSe, ${ }^{19-24} \mathrm{CdTe}^{25} \mathrm{PbS}^{15}{ }^{15} \mathrm{CuInS}_{2}{ }^{26,27}$ ) were used for the preparation of hybrid solar cells. The maximum power conversion efficiencies of hybrid solar cells are today around $4.7 \%$ realised with CdSe/polymer ${ }^{22}$ and CdTe/polymer ${ }^{25}$ hybrid materials. Because of the above mentioned challenges of limited hole mobility and the advantage of an extended absorption range, the tandem concept should contribute to a significant increase of the power conversion efficiencies (PCEs) of hybrid solar cells in the future. 
In this work, we explore the application of polymer/ nanoparticle hybrid solar cells in tandem architecture. First, nanoparticle/polymer-PC ${ }_{61} \mathrm{BM}$ ([6,6]-phenyl $\mathrm{C}_{61}$ butyric acid methyl ester)/polymer tandem solar cells (hybrid-organic tandem solar cells) were realised using a hybrid poly [(2,7-silafluorene)-alt-(4,7-di-2-thienyl-2,1,3-benzothiadiazole)] (PSiF-DBT)/copper indium sulphide (CIS) bottom cell and a $\operatorname{poly}\left(\left\{4,8\right.\right.$-bis [(2-ethylhexyl)oxy]benzo[1,2- $\left.b: 4,5-b^{\prime}\right]$ dithiophene2,6-diyl $\}\{3$-fluoro-2-[(2-ethylhexyl)carbonyl]thieno $[3,4$-b] thiophenediyl $\}$ ) (PTB7)/ $\mathrm{PC}_{61} \mathrm{BM}$ top cell. Secondly, polymer/ nanoparticle-polymer/nanoparticle (hybrid-hybrid) tandem solar cells were fabricated consisting of two PSiF-DBT/CIS hybrid solar cells. The hybrid PSiF-DBT/CIS solar cells are prepared via the xanthate route, which has been recently introduced for the preparation of polymer/CdS ${ }^{28}$ and polymer/ $\mathrm{CIS}^{26}$ hybrid solar cells. Following this route, the nanoparticles are formed in situ in the matrix of the conjugated polymer by conversion of the metal xanthate precursors to metal sulphide nanoparticles during a mild thermal annealing step. The advantage of this in situ route is that no capping agents, which would hinder charge separation and transport in the active layer, ${ }^{29,30}$ are necessary for the stabilisation of the nanoparticles. The growth of the metal sulphide nanoparticles is thereby controlled by the polymer matrix. Alternatively to conjugated polymers, solution-processable small molecules can fulfil this task. ${ }^{31}$ In addition, the active layer can be prepared without tedious nanoparticle synthesis and ligand exchange processes by a facile, short and mild thermal annealing step. The organic moieties of the metal xanthate precursors have been additionally tailored to guarantee high solubility in organic solvents and to form the metal sulphides at low temperatures.

\section{Experimental}

\subsection{Device fabrication}

The hybrid-organic and hybrid-hybrid tandem solar cells were fabricated on glass/ITO substrates (Kintec Company, Hong Kong) with a sheet resistance of $10 \Omega$ /square, which were cleaned in deionised water and isopropanol in an ultrasonic bath followed by $\mathrm{O}_{2}$ plasma cleaning (FEMTO, Diener Electronic, Germany). The PEDOT:PSS layers (Clevios P VP. $\mathrm{Al} 4083$, Heraeus, pure or $1: 1(\mathrm{v} / \mathrm{v})$ diluted with water) were spin coated at $2500 \mathrm{rpm}$ with an acceleration of $300 \mathrm{rpm} / \mathrm{s}$ for $30 \mathrm{~s}$ and were afterwards annealed at $150{ }^{\circ} \mathrm{C}$ for $10 \mathrm{~min}$ in a glove box. The precursor layer for the hybrid absorber layer, consisting of a copper and indium xanthate mixture (1 : 1.7 wt\%, obtained from Aglycon, Austria) with PSiF-DBT (1Material, Chemsitech Inc., Canada), was deposited by doctor blading, followed by a thermal conversion step at a temperature of $195{ }^{\circ} \mathrm{C}$ on a programmable heating plate (CAT Ingenieurbüro $\mathrm{M}$. Zipperer $\mathrm{GmbH}$, Germany; temperature program: heating with a rate of $11{ }^{\circ} \mathrm{C} \mathrm{min}^{-1}$ to a temperature of $195{ }^{\circ} \mathrm{C}$ and holding this temperature for $30 \mathrm{~min}$ ). The polymer to nanoparticle ratio was $1: 9$ per weight, the concentration of the polymer in chlorobenzene was $5 \mathrm{mg}$ $\mathrm{mL}^{-1}$. The synthesis of the xanthate precursors and the thermal conversion step in order to obtain CIS nanoparticles has been described elsewhere. ${ }^{26}$ As recombination layers $\mathrm{Ag} /$ PEDOT:PSS, $\mathrm{TiO}_{x} /$ PEDOT:PSS, $\mathrm{TiO}_{x} / \mathrm{Ag} / \mathrm{PEDOT}$ :PSS and pure PEDOT:PSS were investigated. The metallic interlayers and electrodes were deposited via an evaporation unit inside a glovebox system (LABmaster dp, MBRAUN Glovebox Technology, Germany) at a base pressure of $8^{*} 10^{-6}$ mbar (4 $\mathrm{nm})$. The second PEDOT:PSS layer was prepared by doctor blading of a PEDOT:PSS:isopropanol solution (1: $5 \mathrm{v} / \mathrm{v})$ at a temperature of $60{ }^{\circ} \mathrm{C}$ and was dried under vacuum for $10 \mathrm{~min}$. The PTB7/PC ${ }_{61} \mathrm{BM}$ (1:1.5 by weight; the concentration of the polymer solution was $10 \mathrm{mg} \mathrm{mL}^{-1}$; PTB7 was purchased at 1-Material, Chemsitech Inc., Canada; $\mathrm{PC}_{61} \mathrm{BM}$ at Solenne BV, Groningen, The Netherlands) layer was prepared by doctor blading a mixture of chlorobenzene/1,8-diiodoctane (97 : 3\% by volume $)^{6}$ solution on top of the PEDOT:PSS layer. $180 \mathrm{~nm}$ thick $\mathrm{Al}$ electrodes for the hybrid-organic tandem devices and $2 \mathrm{~nm} \mathrm{Ag}$ and $200 \mathrm{~nm} \mathrm{Al}$ for the hybrid-hybrid devices were subsequently thermally evaporated inside a glovebox system. For comparison, single junction solar cells were also fabricated with the device structure glass/ITO/PEDOT:PSS/PSiFDBT/CIS/TiO $/$ Ag for the hybrid solar cell and glass/ITO/ PEDOT:PSS/PTB7/ $\mathrm{PC}_{61} \mathrm{BM} / \mathrm{Al}$ for the organic solar cell.

\subsection{Characterisation and measurement}

PCE values were determined from I-V curves recorded using a Keithley 2400 SourceMeter, a custom made Lab-View software and a Dedolight DLH400D lamp. The light intensity was set to $100 \mathrm{~mW} \mathrm{~cm}^{-2}$ providing a spectrum quite similar to AM1.5G (determined using a KippZonen-CMP-11 pyranometer, no spectral mismatch was considered). The effective device area $\left(0.04 \mathrm{~cm}^{2}\right)$ was defined by $2 \times 2 \mathrm{~mm}^{2}$ shadow masks applied to the solar cells during the measurements of the I-V curves. IPCE spectra were obtained from a MuLTImode 4 monochromator equipped with a xenon lamp (AMKO) and a Keithley 2400 SourceMeter. Absorption spectra were recorded with a Shimadzu UV-1800 spectrophotometer or with a Perkin Elmer UV/VIS spectrometer Lambda 35. SEM analyses were conducted on a Zeiss Ultra 55 and the cross section for this characterisation was realised by large area ion milling using a Gatan Ilion $^{+\mathrm{TM}}$. Layer thicknesses were determined on a Bruker DekTak XT surface profiler.

\section{Results and discussion}

Up to now there are no reports about polymer/nanoparticle hybrid solar cells in tandem architectures. Therefore, it is necessary to investigate if series connection via recombination layers known from organic tandem solar cells is possible and if the hybrid absorber layers are inert to further processing steps during the preparation of the tandem solar cells. This is especially challenging for double hybrid tandem solar cells prepared via the in situ route, where thermal annealing is required for the preparation of both absorber layers, and thus, the bottom cell experiences more thermal stress. To separate this issue from finding a suitable recombination layer, we combined in a first step an in situ 


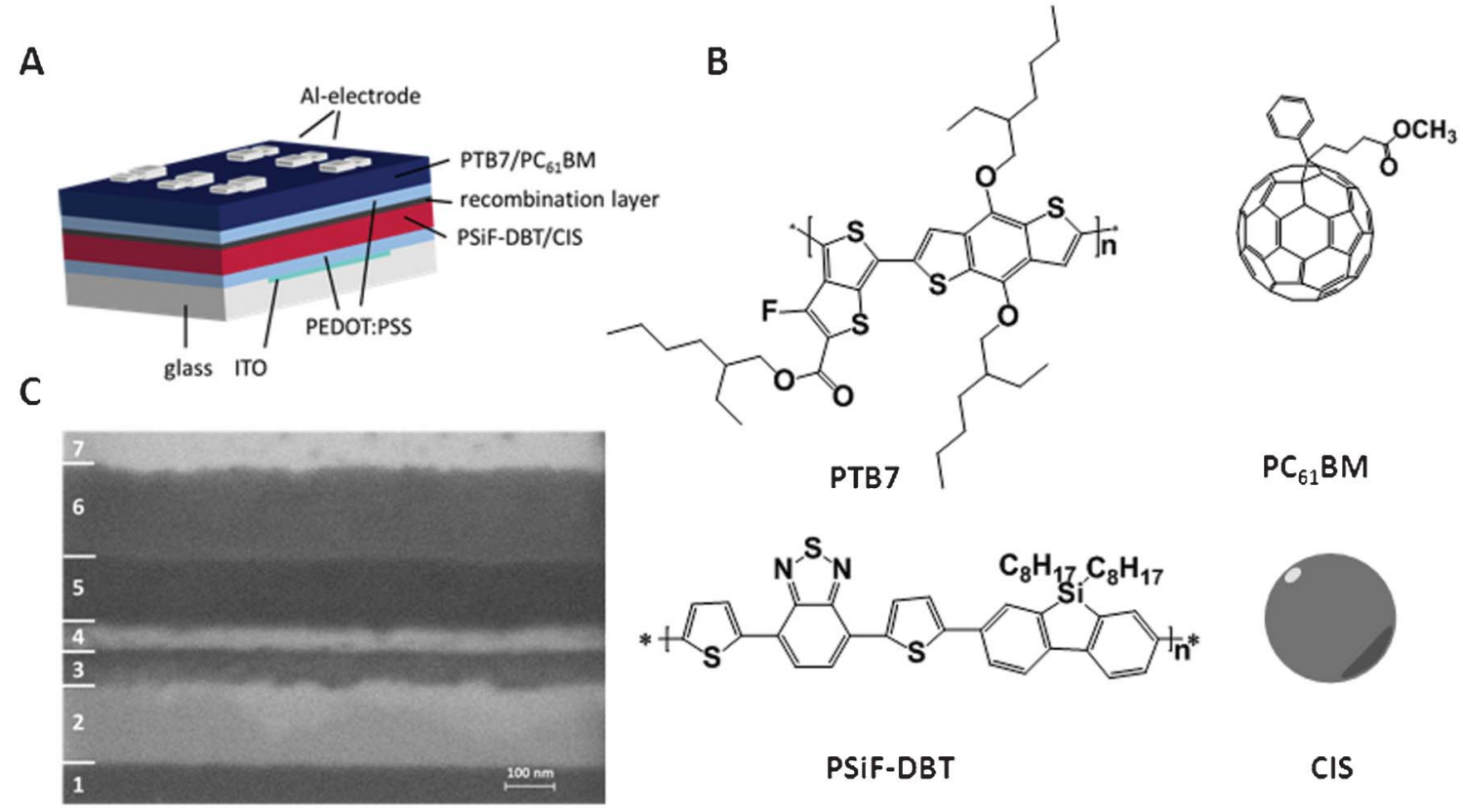

Fig. 1 (A) Device architecture of the hybrid-organic tandem solar cell; (B) corresponding chemical structures of the absorber layers; (C) SEM image of an ion milled cross section: 1: glass, 2: ITO, 3: PEDOT:PSS, 4: PSiF-DBT/CIS, 5: PEDOT:PSS \& PTB7/PCBM, 6: Al electrode, 7: protection layer.

prepared hybrid PSiF-DBT/CIS bottom cell with a polymer/ PCBM top cell, which does not need a thermal treatment during preparation, in the tandem architecture. Fig. 1A shows the device geometry of the prepared hybrid organic tandem solar cell. We chose $\mathrm{PTB} 7 / \mathrm{PC}_{61} \mathrm{BM}$ as material for the organic solar cell because the absorption profile of this material combination complements the absorption of the PSiF-DBT/ CIS hybrid material quite well in order to harvest an increased amount of light (for the chemical structures of the polymers see Fig. 1B).

The PSiF-DBT/CIS bottom cells as well as corresponding reference cells were prepared via an in situ preparation route. ${ }^{26}$ Thus, a common solution of $\mathrm{Cu}$ and In xanthates with the conjugated polymer is coated directly on the PEDOT:PSS layer already deposited onto ITO-glass substrates. The metal xanthates are subsequently converted to copper indium sulphide nanoparticles directly within the polymer matrix at a temperature of $195{ }^{\circ} \mathrm{C}$. On top of this layer, either the recombination layer was deposited for the tandem cells (vide infra) or an $\mathrm{Ag}(2 \mathrm{~nm}) / \mathrm{Al}(180 \mathrm{~nm})$ back electrode ${ }^{32}$ was vapour deposited for the reference cells. The $\mathrm{PTB} 7 / \mathrm{PC}_{61} \mathrm{BM}$ top cell as well as reference cells were knife coated from chlorobenzene solutions containing 1,8-diiodooctane ( 3 vol\%) following a modified literature protocol. ${ }^{6}$ The solar cell fabrication was completed by deposition of Al back electrodes.

Before focusing on the tandem cells, the optical properties of both materials combinations as well as the solar cell parameters of the corresponding single cells are discussed. The absorption spectra of PSiF-DBT and PTB7 (Fig. 2A) complement each other and make these two polymers suitable for the use in tandem devices. The absorption spectrum of
PSiF-DBT exhibits two maxima; the first is located at $400 \mathrm{~nm}$ and the second at $570 \mathrm{~nm}$ whereas the absorption maximum of PTB7 appears at $670 \mathrm{~nm}$.
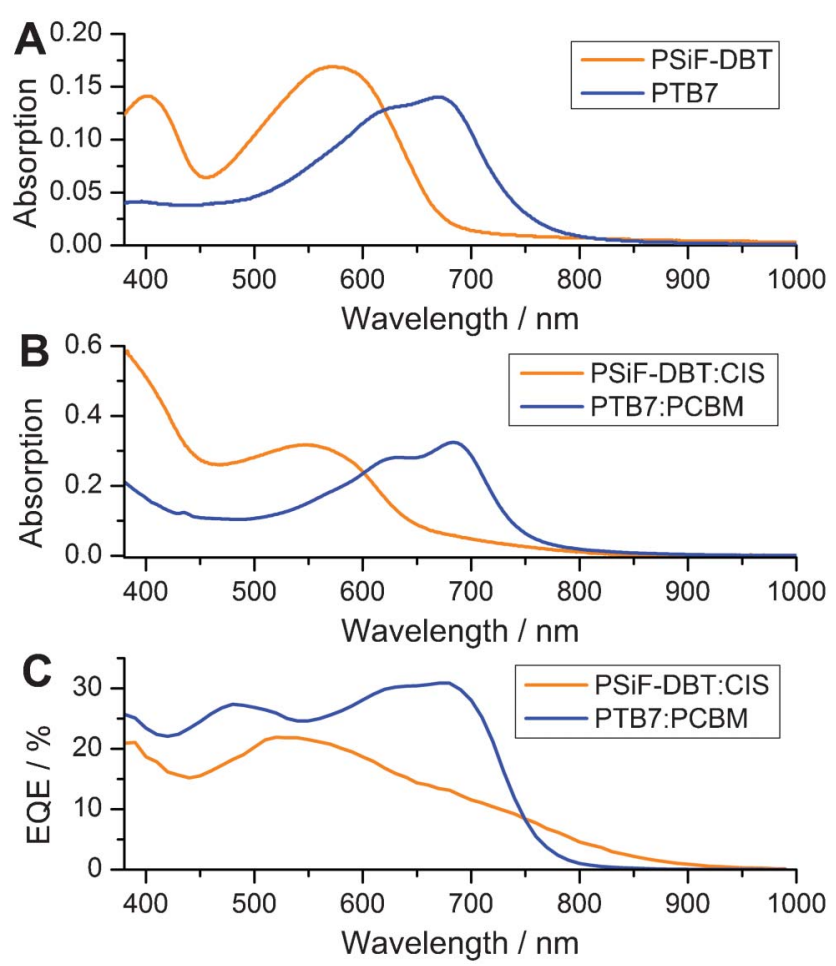

Fig. 2 Absorption spectra of PSiF-DBT and PTB7 (A), absorption spectra of the two absorber layers (PSiF-DBT/CIS and PTB7/PCBM) (B) and EQE spectra of the corresponding solar cells (C). 
A comparison of the absorption spectra of the pure polymers (Fig. 2A) with the absorption spectra of the bulkheterojunction layers (Fig. 2B) evidences that in the case of the PSiF-DBT/CIS hybrid layer the nanoparticle phase contributes to the absorption especially between $700 \mathrm{~nm}$ and $850 \mathrm{~nm}$. The spectrum of the $\mathrm{PTB} 7 / \mathrm{PC}_{61} \mathrm{BM}$ layer is dominated by the absorption features of the polymer. The EQE spectra of the corresponding PSiF-DBT/CIS as well as the PTB7/PCBM single solar cells are depicted in Fig. 2C. In the EQE spectrum of the PSiF-DBT/CIS solar cell, the maximum in photocurrent generation is blue-shifted compared to the maximum of the PSiF-DBT/CIS absorption spectrum. This is most presumably caused by the fact that the contribution to current generation of the amorphous part of the polymer is more dominant compared to semicrystalline parts. ${ }^{33}$ Furthermore, the EQE of the PSiF-DBT/CIS absorber layers evidences that the copper indium sulphide nanoparticles significantly contribute to the current generation. The EQE spectrum of the PTB7/PCBM solar cell shows also a charge generation over a broad wavelength range (approx. 750-400 nm) and is consistent with previous literature reports. ${ }^{34}$

Fig. 3 shows the current density-voltage (I-V) characteristics of the two single cells and the corresponding tandem cell under AM1.5 simulated illumination with an intensity of 100 $\mathrm{mW} \mathrm{cm}^{-2}$.

The hybrid solar cell (PSiF-DBT/CIS) exhibited an open circuit voltage $\left(V_{\mathrm{OC}}\right)$ of $0.44 \mathrm{~V}$, a short circuit current density $\left(I_{\mathrm{SC}}\right)$ of $8.19 \mathrm{~mA} \mathrm{~cm}^{-2}$, a fill factor $(\mathrm{FF})$ of 0.51 and a PCE of $1.81 \%$. The organic single cell ( $\left.\mathrm{PTB} 7 / \mathrm{PC}_{61} \mathrm{BM}\right)$ exhibited a $V_{\mathrm{OC}}$ of $0.56 \mathrm{~V}$, a J JC of $10.4 \mathrm{~mA} \mathrm{~cm} \mathrm{~cm}^{-2}$, a FF of 0.61 and a PCE of $3.51 \%$. The obtained efficiency for the $\mathrm{PTB} 7 / \mathrm{PC}_{61} \mathrm{BM}$ solar cells is lower in contrast to recently reported PCE values for PTB7 fullerene solar cells (7.4\% and 9.2\%). ${ }^{6,35}$ In these cases, $\mathrm{PC}_{71} \mathrm{BM}$ which usually gives higher efficiencies as well as additional interlayers (polymeric polyelectrolyte interlayers) were used. However, the incorporation of such interlayers increased mainly the $I_{\mathrm{SC}}$ values, which is in view of our experiments not necessary. The $I_{\mathrm{SC}}$ of tandem devices is limited by the lowest value of the involved subcells. The $I_{\mathrm{SC}}$ of the $\mathrm{PTB} 7 / \mathrm{PC}_{61} \mathrm{BM}$ solar cell is without interlayers already higher than the $I_{\mathrm{SC}}$ of the PSiF-DBT/CIS hybrid solar cell. To connect the two single cells in series we investigated different interlayer combinations. These interlayers have to be sufficient conductive and transparent and have to provide high charge carrier mobility, so that no charge trapping occurs. ${ }^{3}$ Moreover, the interlayer has to efficiently collect electrons from one subcell and holes from the other and should provide an efficient recombination zone without any potential loss. ${ }^{3}$ Ultrathin metal films of silver ${ }^{36}$ and gold, ${ }^{37}$ vacuum deposited metal oxides like indium tin oxide (ITO) ${ }^{38}$ molybdenum oxide $\left.\left(\mathrm{MoO}_{3}\right)\right)^{39-41}$ or solution processed metal oxides such as $\mathrm{TiO}_{x}{ }^{42}$ and $\mathrm{ZnO}^{43}$ are described in the literature. Mostly, these metal oxides are used in combination with PEDOT:PSS. We investigated Ag/PEDOT:PSS (poly(3,4-ethylenedioxylenethiophene)-polystyrene sulphonic acid), $\mathrm{TiO}_{x} /$ PEDOT:PSS and a single PEDOT:PSS layer. Whereas the $\mathrm{Ag}$ layer was directly evaporated in the glovebox, the $\mathrm{TiO}_{x}$ layer was prepared by evaporation of $4 \mathrm{~nm}$ of metallic Ti in the glovebox which is subsequently converted to $\mathrm{TiO}_{x}$ by exposure to air. Ti has a very high affinity to oxygen and forms within $\mu$ s an oxide layer with a thickness of $2-5 \mathrm{~nm}^{44,45}$ Fig. 3B shows the I-V characteristics of hybrid-organic tandem cells with different recombination layers and Table 1 summarises the characteristic parameters of the prepared tandem devices (characteristic parameters of five typical devices of each case can be found in Table S1 in the ESI†). As can be seen from the characteristic parameters and the I-V curves in Fig. 3B, the interlayer plays an important role in the device performance of the tandem cell. The device with Ag/PEDOT:PSS interlayer exhibited the highest $V_{\mathrm{OC}}$ with a value of $1 \mathrm{~V}$ which is exactly the sum of the values of both single cells. Whereas the fill factor has a value of $56 \%$ and is still high, the $I_{\mathrm{SC}}$ drastically drops to only half of the value of the PSiF-DBT/CIS hybrid cells. Thus, the overall efficiency only yields a value of $2.1 \%$, which is lower than the
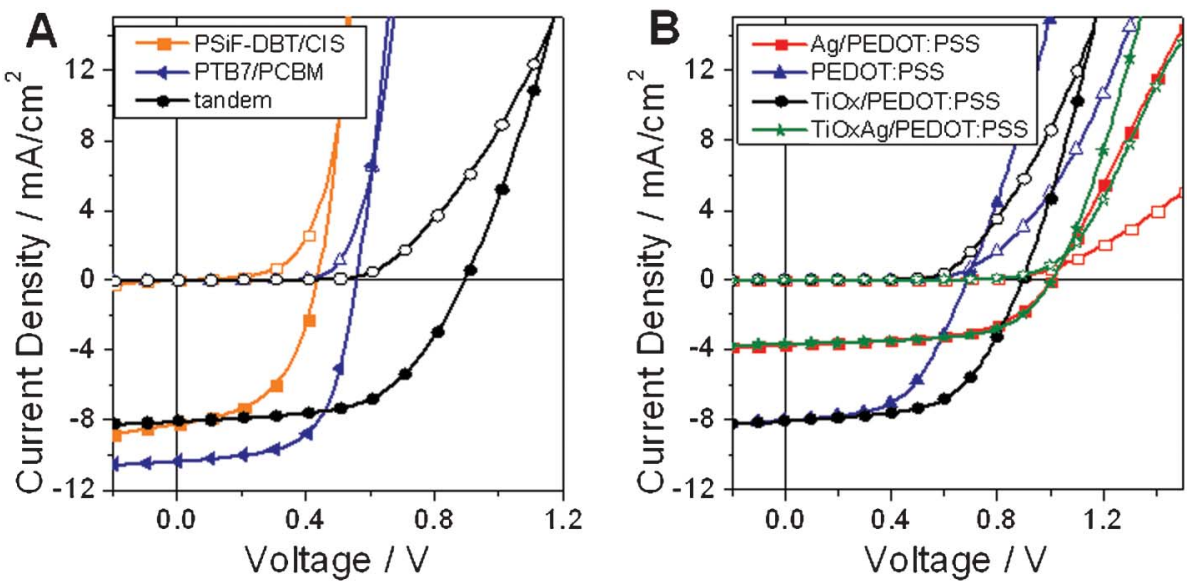

Fig. $3 \mathrm{~A}$ : I-V characteristics of the single cells in comparison to the optimised hybrid-organic tandem cell in the dark (open symbols) and $\mathrm{under} 100 \mathrm{~mW} \mathrm{~cm}^{-2}$

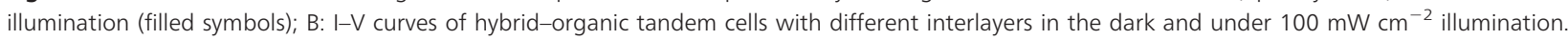


Table 1 Characteristic parameters of PSiF-DBT/CIS and PTB7/PC ${ }_{61}$ BM solar cells, hybrid-organic (PSiF-DBT/CIS/PTB7/PC 61 BM) tandem solar cells and hybrid-hybrid (PSiF-DBT/CIS/PSiF-DBT/CIS) tandem solar cells using different recombination layers

\begin{tabular}{|c|c|c|c|c|c|c|}
\hline & & & $V_{\mathrm{OC}} / \mathrm{V}$ & $I_{\mathrm{SC}} / \mathrm{mA} \mathrm{cm}^{-2}$ & $\mathrm{FF}$ & Eff. $/ \%$ \\
\hline \multirow[t]{2}{*}{ Single } & & PSiF-DBT/CIS & 0.44 & 8.19 & 0.51 & 1.8 \\
\hline & & $\mathrm{PTB} 7 / \mathrm{PC}_{61} \mathrm{BM}$ & 0.56 & 10.4 & 0.61 & 3.5 \\
\hline & \multirow{3}{*}{ Hybrid-organic } & PEDOT:PSS & 0.69 & 7.99 & 0.53 & 2.9 \\
\hline & & TiO $_{x} /$ PEDOT:PSS & 0.90 & 8.04 & 0.57 & 4.1 \\
\hline & & $\mathrm{TiO}_{x} / \mathrm{Ag} / \mathrm{PEDOT}: \mathrm{PSS}$ & 1.01 & 3.72 & 0.56 & 2.1 \\
\hline & Hybrid-hybrid & Ag/PEDOT:PSS & 0.72 & 4.19 & 0.42 & 1.3 \\
\hline
\end{tabular}

efficiency of the single PTB7/PCBM solar cell. This loss in $I_{\mathrm{SC}}$ with $\mathrm{Ag}$ recombination layers has already been reported for organic tandem solar cells and could be caused by the reduced transmittance of the $\mathrm{Ag}$ interlayer in the wavelength range of 400-800 nm. ${ }^{46}$ The hybrid-organic tandem solar cell with a single PEDOT:PSS interlayer showed a $V_{\text {OC }}$ of about $0.69 \mathrm{~V}$, which was higher than the $V_{\mathrm{OC}}$ of the single cells, but far away from the theoretical possible value, the sum of both $V_{\mathrm{OC}} \mathrm{S}$. The $I_{\mathrm{SC}}$ of the tandem device reaches almost the $I_{\mathrm{SC}}$ of the hybrid single solar cells, and was doubled compared to the tandem cell with the Ag/PEDOT:PSS layer. The best performance could be realised with a tandem device comprising a $\mathrm{TiO}_{x} /$ PEDOT:PSS recombination layer. The $V_{\text {OC }}$ with $0.90 \mathrm{~V}$ was slightly lower than the sum of the $V_{\mathrm{OC}} \mathrm{S}$ of the single cells (PSiFDBT/CIS: $0.44 \mathrm{~V}$ and PTB7/PCBM: $0.56 \mathrm{~V})$ but the $I_{\mathrm{SC}}(8.04 \mathrm{~mA}$ $\mathrm{cm}^{-2}$ ) also catches up with the value of the PSiF-DBT/CIS hybrid cells leading to a power conversion efficiency of $4.1 \%$.

To complete the series, we have also investigated a combined $\mathrm{Ag} / \mathrm{TiO}_{x} / \mathrm{PEDOT}$ :PSS interlayer. However, the tandem solar cells show the same solar cell characteristics as those prepared with the Ag/PEDOT:PSS interlayer, high $V_{\mathrm{OC}} \mathrm{S}$ but only half of the theoretical $I_{\mathrm{SC}}$ values (see Table 1 ).

Fig. 1C shows a SEM image of an ion milled cross section of the hybrid-organic tandem cell which showed the best performance $(4.1 \%)$ in this series. The tandem structure (1: glass; 2: ITO; 3: PEDOT:PSS; 4: PSiF-DBT/CIS; 5: PEDOT:PSS \& $\mathrm{PTB} 7 / \mathrm{PCBM}$; 6: Al; 7: protection layer) is precisely visible in the micrograph, the layers are smooth and the PSiF-DBT/CIS layer with a thickness of $80 \mathrm{~nm}$ is clearly identifiable. However, it is not possible to distinguish between the different organic materials (PTB7/PCBM and PEDOT:PSS), so the second PEDOT:PSS layer and the subsequent $\mathrm{PTB} / / \mathrm{PC}_{61} \mathrm{BM}$ layer appear as one single layer with a thickness of $140 \mathrm{~nm}$. As expected, the $\mathrm{TiO}_{x}$ layer is not visible at all because of its thickness of only $4 \mathrm{~nm}$. Also due to the limited resolution of SEM, the phase separation as well as single nanoparticles are not identifiable. However, TEM images from equally prepared PSiF-DBT/CIS absorber layers presented in a previous publication, ${ }^{26}$ show that copper indium sulphide nanoparticles of approx. $5 \mathrm{~nm}$ are formed in the polymer matrix and no larger agglomerates are present in the layer. Additionally to SEM characterisation, we used a surface profiler to determine the accurate layer thicknesses. The measured values match well with the results of the SEM investigation of the cross section. The PSiF-DBT/CIS layer exhibits a thickness of 60-80 nm, the PTB7/PCBM layer has a thickness of 90-110 nm, the PEDOT:PSS layer of the bottom cell has a thickness of 50-60 $\mathrm{nm}$ and the one of the top cell $20-30 \mathrm{~nm}$. From these first results it can be concluded that tandem solar cells with PCEs of $5 \%$ should be achievable by further optimisation and lossfree series connection of the two single cells. The best tandem solar cell we obtained in our experiments so far, uses a $\mathrm{TiO}_{x} /$ PEDOT:PSS recombination layer and shows a power conversion efficiency of $4.1 \%$, which is $82 \%$ of the theoretically possible value.

To go one step further, in a second series, we investigated tandem solar cells with two PSiF-DBT/CIS absorber layers to show a first example of a hybrid-hybrid tandem solar cell. As mentioned above, this approach is challenging because the absorber layers are prepared via an in situ method, in which thermal annealing is required for the fabrication of both absorber layers, leading to additional thermal stress for the bottom cell during the production process of the top cell. Preliminary tests on single cells have shown that a second annealing step does not significantly decrease the solar cell performance, thus, in situ prepared hybrid-hybrid tandem solar cells should be realisable by applying the same conversion parameters $\left(15 \mathrm{~min}\right.$ from $30{ }^{\circ} \mathrm{C}$ to $195{ }^{\circ} \mathrm{C}, 15 \mathrm{~min}$ $195{ }^{\circ} \mathrm{C}$ ) for both absorber layers. So we prepared a series of hybrid-hybrid tandem solar cells using the same interlayer combinations, tested in the first series. The I-V curves of all these tandem solar cells are presented in Fig. 4A.

Although the $\mathrm{TiO}_{x} /$ PEDOT:PSS interlayer exhibited the best performance in the hybrid-organic tandem cell, this interlayer did not lead to properly working hybrid-hybrid tandem solar cells. The two subcells were not successfully connected in series which was revealed by the low open circuit voltage of only $0.46 \mathrm{~V}$ of the tandem device, which matches with the $V_{\mathrm{OC}}$ of the PSiF-DBT single cell. Furthermore, the $I_{\mathrm{SC}}$ exhibited a value of $4.60 \mathrm{~mA} \mathrm{~cm}{ }^{-2}$ which is only $50 \%$ of the $I_{\mathrm{SC}}$ of the hybrid single cell and the FF decreased to a value of 0.32 leading to a PCE of only $0.7 \%$. One possible explanation for that may be that the $\mathrm{TiO}_{x}$ layer is not stable in the thin layer during the annealing step of the hybrid top cell. The pure 
A

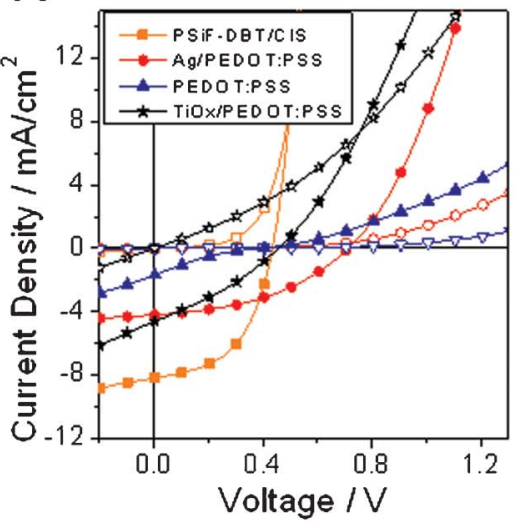

B

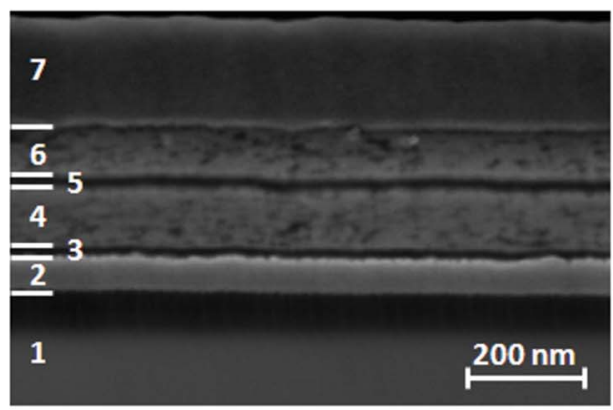

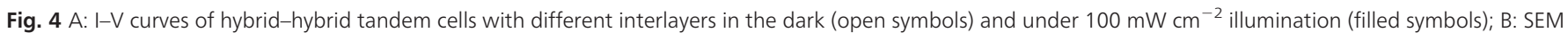

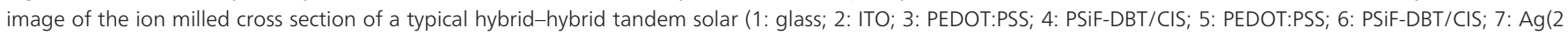
$\mathrm{nm}$, not visible)/Al).

PEDOT:PSS interlayer exhibited an even lower $V_{\text {OC }}$ of $0.38 \mathrm{~V}$ compared to the single cells, a drop in $I_{\mathrm{SC}}$ to $1.68 \mathrm{~mA} \mathrm{~cm}^{-2}$ and a FF of only 0.18 , which stems from a S-shaped curve in the I-V characteristic of the light exposed cell. Similar S-shaped curves were also already observed in the literature for tandem solar cells using only PEDOT:PSS as interlayer. ${ }^{38,40}$

However, with an Ag/PEDOT:PSS interlayer well working hybrid-hybrid tandem solar cells, exhibiting an increase in $V_{\text {OC }}$ up to $81 \%$ of the sum of the $V_{\text {OC }}$ of the single cells, were achieved. Fig. 4A shows the I-V characteristics of the single cell in comparison with the different tandem cell approaches under $100 \mathrm{~mW} \mathrm{~cm}{ }^{-2}$ illumination. Although the $V_{\mathrm{OC}} \mathrm{S}$ of the single cells are nearly added, the $I_{\mathrm{SC}}\left(4.19 \mathrm{~mA} \mathrm{~cm}^{-2}\right)$ as well as FF (0.42) decreased, compared to the single cells, which led to an efficiency of the hybrid-hybrid tandem solar cell of $1.3 \%$.

Fig. 4B shows a SEM image of an ion milled cross section of a typical hybrid-hybrid tandem solar cell consisting of two PSiF-DBT/CIS subcells. The arrangement of the different layers, except of the several nm thick Ag-interlayers, are clearly visible in this image (glass/ITO/PEDOT:PSS/PSiF-DBT/CIS/Ag (not visible)/PEDOT:PSS/PSiF-DBT/CIS/Ag (not visible)/Al). However, the layers seem to be very homogeneous and smooth with thicknesses of 80-100 $\mathrm{nm}$ for the PSiF-DBT/CIS layers and $15 \mathrm{~nm}$ for the PEDOT:PSS layers determined from the cross section, although the first active layer has to undergo thermal treatment twice.

To improve the efficiency of in situ prepared hybrid-hybrid tandem solar cells it is necessary to do further research in order to find a suitable recombination layer which is not affected by the thermal treatment of the top cell and does not limit the $I_{\mathrm{SC}}$ and FF. To further enhance the $I_{\mathrm{SC}}$ and thus the PCE it is also necessary to use two different absorber layers so that the absorption of the tandem solar cell is extended. With this hybrid-hybrid tandem approach, it is possible to tune the overall absorption of hybrid tandem solar cells with four components, the two polymers and two different inorganic semiconductors e.g. $\mathrm{P} 3 \mathrm{HT} / \mathrm{CdS},{ }^{18} \mathrm{PDTPBT} / \mathrm{PbS}^{15}$ which opens a huge playground for further research.

\section{Conclusions}

In summary, we have successfully prepared hybrid-organic as well as hybrid-hybrid tandem solar cells and we compared the effects of different recombination layers on the device performance. The solar cell characteristics indicate that the $\mathrm{TiO}_{x} /$ PEDOT:PSS interlayer can provide an efficient recombination region in hybrid-organic solar cells, leading to a hybrid-organic tandem cell with a $V_{\text {OC }}$ of $0.90 \mathrm{~V}$, which is $91 \%$ of the sum of the subcell $V_{\mathrm{OC}}$ values. The $I_{\mathrm{SC}}$ seems to be limited by the single cell with the lower $I_{\mathrm{SC}}$ value reaching a PCE of $4.1 \%$ which is an increase in device performance compared to the single cells.

In contrast to this, $\mathrm{TiO}_{x} /$ PEDOT:PSS is not a suitable recombination layer for the hybrid-hybrid tandem device, as here this interlayer does not lead to an increase in $V_{\mathrm{OC}}$ compared to the single cells. The Ag/PEDOT:PSS interlayer showed the best performance in this case. As in the hybridorganic tandem solar cell also in the hybrid-hybrid device, this interlayer exhibited the highest $V_{\text {OC }}$ but only approximately the half of the $I_{\mathrm{SC}}$ of the single hybrid cell is maintained in the tandem structure. Nevertheless, first working hybrid-hybrid tandem solar cells were obtained, showing a power conversion efficiency of $1.3 \%$. The $V_{\text {OC }}$ of the single cells is nearly doubled. However, the quite low $I_{\mathrm{SC}}$ provides the necessity for further improvement of the recombination layer. The SEM pictures of the two tandem device architectures showed smooth layers indicating that in the hybrid-hybrid device the second heating step did not significantly affect the morphology. In this study we demonstrate the possibility to use the in situ synthesis route also in preparation of tandem solar cells. The presented concept of hybrid-hybrid tandem solar cells provides the potential for further enhancement of 
light absorption by the usage of two organic and two inorganic semiconducting materials with complementary absorption profiles in two absorber layers.

\section{Acknowledgements}

Financial support by the Christian Doppler Research Association, the Austrian Federal Ministry of Economy, Family and Youth (BMWFJ), and ISOVOLTAIC AG is gratefully acknowledged. The authors thank Lukas Troi for his support constructing custom made measurement cells for I-V and EQE characterisation and Sebastian Rauch for the preparation of the ion milled cross section of a solar cell.

\section{References}

1 T. Ameri, G. Dennler, C. Lungenschmied and C. J. Brabec, Energy Environ. Sci., 2009, 2, 347-363.

2 M. K. Siddiki, J. Li, D. Galipeau and Q. Qiao, Energy Environ. Sci., 2010, 3, 867-883.

3 S. Sista, Z. Hong, L.-M. Chen and Y. Yang, Energy Environ. Sci., 2011, 4, 1606-1620.

4 J. Gilot, M. M. Wienk and R. A. J. Janssen, Adv. Mater., 2010, 22, E67-E71.

5 T. T. Larsen-Olsen, E. Bundgaard, K. O. Sylvester-Hvid and F. C. Krebs, Org. Electron., 2011, 12, 364-371.

6 Z. He, C. Zhong, S. Su, M. Xu, H. Wu and Y. Cao, Nat. Photonics, 2012, 6, 591-595.

7 Press release - Heliatek, http:/www.heliatek.com/newscenter/latest_news/neuer-weltrekord-fur-organische-solarzellen-heliatek-behauptet-sich-mit-12-zelleffizienz-als-technologiefuhrer/?lang=en, accessed on March 25, 2013.

8 J. You, L. Dou, K. Yoshimura, T. Kato, K. Ohya, T. Moriarty, K. Emery, C.-C. Chen, J. Gao, G. Li and Y. Yang, Nat. Commun., 2013, 4, 1446.

9 J. You, C.-C. Chen, Z. Hong, K. Yoshimura, K. Ohya, R. Xu, S. Ye, J. Gao, G. Li and Y. Yang, Adv. Mater., 2013, 25, 3973-3978.

10 B. R. Saunders, J. Colloid Interface Sci., 2012, 369, 1-15.

11 R. Zhou and J. Xue, ChemPhysChem, 2012, 13, 2471-3480.

12 M. Wright and A. Uddin, Sol. Energy Mater. Sol. Cells, 2012, 107, 87-111.

13 A. J. Moulé, L. Chang, C. Thambidurai, R. Vidu and P. Stroeve, J. Mater. Chem., 2012, 22, 2351-2368.

14 L. Zhao and Z. Lin, Adv. Mater., 2012, 24, 4353-4368.

15 J. Seo, M. J. Cho, D. Lee, A. N. Cartwright and P. N. Prasad, Adv. Mater., 2011, 23, 3984-3988.

16 S. D. Oosterhout, M. M. Wienk, S. S. van Bavel, R. Thiedmann, L. J. A. Koster, J. Gilot, J. Loos, V. Schmidt and R. A. J. Janssen, Nat. Mater., 2009, 8, 818-824.

17 S. Ren, L.-Y. Chang, S.-K. Lim, J. Zhao, M. Smith, N. Zhao, V. Bulovic, M. Bawendi and S. Gradecak, Nano Lett., 2011, 11, 3998-4002.

18 S. Dowland, T. Lutz, A. Ward, S. P. King, A. Sudlow, M. S. Hill, K. C. Molloy and S. A. Haque, Adv. Mater., 2011, 23, 2739-2744.
19 Y. Zhou, M. Eck, C. Men, F. Rauscher, P. Niyamakom, S. Yilmaz, I. Dumsch, S. Allard, U. Scherf and M. Krüger, Sol. Energy Mater. Sol. Cells, 2011, 95, 3227-3232.

20 S. Dayal, N. Kopidakis, D. C. Olson, D. S. Ginley and G. Rumbles, Nano Lett., 2010, 10, 239-242.

21 J. Albero, Y. Zhou, M. Eck, R. Rauscher, P. Niyamakom, I. Dumsch, S. Allard, U. Scherf, M. Krüger and E. Palomares, Chem. Sci., 2011, 2, 2396-2401.

22 R. Zhou, R. Stalder, D. Xie, W. Cao, Y. Zheng, Y. Yang, M. Plaisant, P. H. Holloway, K. S. Schanze, J. R. Reynolds and J. Xue, ACS Nano, 2013, 7, 4846-4854.

23 R. Zhou, Y. Zheng, L. Qian, Y. Yang, P. H. Holloway and J. Xue, Nanoscale, 2012, 4, 3507-3514.

24 K. F. Jeltsch, M. Schädel, J.-B. Bonekamp, P. Niyamakom, F. Rauscher, H. W. A. Lademann, I. Dumsch, S. Allard, U. Scherf and K. Meerholz, Adv. Funct. Mater., 2012, 22, 397-404.

25 Z. Chen, H. Zhang, X. Du, X. Cheng, X. Chen, Y. Jiang and B. Yang, Energy Environ. Sci., 2013, 6, 1597-1603.

26 T. Rath, M. Edler, W. Haas, A. Fischereder, S. Moscher, A. Schenk, R. Trattnig, M. Sezen, G. Mauthner, A. Pein, D. Meischler, K. Bartl, R. Saf, N. Bansal, S. A. Haque, F. Hofer, E. J. W. List and G. Trimmel, Adv. Energy Mater., 2011, 1, 1046-1050.

27 E. Maier, T. Rath, W. Haas, O. Werzer, R. Saf, F. Hofer, D. Meissner, O. Volobujeva, S. Bereznev, M. Mellikov, H. Amenitsch, R. Resel and G. Trimmel, Sol. Energy Mater. Sol. Cells, 2011, 95, 1354-1361.

28 H. C. Leventis, S. P. King, A. Sudlow, M. S. Hill, K. C. Molloy and S. A. Haque, Nano Lett., 2010, 10, 1253-1258.

29 L. X. Reynolds, T. Lutz, S. Dowland, A. MacLachlan, S. King and S. A. Haque, Nanoscale, 2012, 4, 1561-1564.

30 E. Martinez-Ferrero, J. Albero and E. Palomares, J. Phys. Chem. Lett., 2010, 1, 3039-3045.

31 T. Rath, V. Kaltenhauser, W. Haas, A. Reichmann, F. Hofer and G. Trimmel, Sol. Energy Mater. Sol. Cells, 2013, 114, 38-42.

32 M. Arar, A. Pein, W. Haas, F. Hofer, K. Norrman, F. C. Krebs, T. Rath and G. Trimmel, J. Phys. Chem. C, 2012, 116, 19191-19196.

33 S. D. Oosterhout, M. M. Wienk, M. Al-Hashimi, M. Heeney and R. A. J. Janssen, J. Phys. Chem. C, 2011, 115, 18901-18908.

34 Y. Liang, Z. Xu, J. Xia, S.-T. Tsai, Y. Wu, G. Li, C. Ray and L. Yu, Adv. Mater., 2010, 22, E135-E138.

35 W. Chen, T. Xu, F. He, W. Wang, C. Wang, J. Strzalka, Y. Liu, J. Wen, D. J. Miller, J. Chen, K. Hong, L. Yu and S. B. Darling, Nano Lett., 2011, 11, 3707-3713.

36 A. Yakimov and S. R. Forrest, Appl. Phys. Lett., 2002, 80, 1667-1669.

37 M. Hiramoto, M. Suezaki and M. Yokoyama, Chem. Lett., 1990, 19, 327-330.

38 J. H. Seo, D.-H. Kim, S.-H. Kwon, M. Song, M.-S. Choi, S. Y. Ryu, H. W. Lee, Y. C. Park, J.-D. Kwon, K.-S. Nam, Y. Jeong, J.-W. Kang and C. S. Kim, Adv. Mater., 2012, 24, 4523-4527.

39 D. W. Zhao, X. W. Sun, C. Y. Jiang, A. K. K. Kyaw, G. Q. Lo and D. L. Kwong, Appl. Phys. Lett., 2008, 93, 083305.

40 T. Kim, J. H. Jeon, S. Han, D.-K. Lee, H. Kim, W. Lee and K. Kim, Appl. Phys. Lett., 2011, 98, 183503. 
41 J. Sakai, K. Kawano, T. Yamanari, T. Taima, Y. Yoshida, A. Fujii and M. Ozaki, Sol. Energy Mater. Sol. Cells, 2010, 94, 376-380.

42 J. Y. Kim, K. Lee, N. E. Coates, D. Moses, T.-Q. Nguyen, M. Dante and A. J. Heeger, Science, 2007, 317, 222-225.

43 J. Gilot, M. M. Wienk and R. J. Janssen, Appl. Phys. Lett., 2007, 90, 143512.
44 M. Polak, Ph.D. Thesis, Ernst-Moritz-Arndt University, Greifswald, 2009.

45 B. Kasemo and J. Lausmaa, J. Biomed. Mater. Res., 1988, 22, 145-158.

46 F.-C. Chen and C.-H. Lin, J. Phys. D: Appl. Phys., 2010, 43, 025104. 